\title{
Comparative Genomic Studies of hypothetical proteins in Cyanophages
}

\author{
S. G. Sanmukh \\ Applied Aquatic Eco-system \\ Division, \\ National Environmental \\ Engineering Research Institute \\ (NEERI) \\ Nehru Marg, Nagpur-440020, \\ Maharashtra (India)
}

\author{
M. Rahman \\ Applied Aquatic Eco-system \\ Division, \\ National Environmental \\ Engineering Research Institute \\ (NEERI) \\ Nehru Marg, Nagpur-440020, \\ Maharashtra (India)
}

\author{
W. N. Paunikar \\ Applied Aquatic Eco-system \\ Division, \\ National Environmental \\ Engineering Research Institute \\ (NEERI) \\ Nehru Marg, Nagpur-440020, \\ Maharashtra (India)
}

\begin{abstract}
The Cyanophages are the phages infecting cyanobacteria. They are potential agents for the horizontal gene transfer. The complete genome of 10 known Cyanophages deciphered the presence of various gene sequences for hypothetical proteins whose functions are not yet understood. Our attempt is to predict the structure and function of these hypothetical proteins by the application of computational methods and Bioinformatics. The probable function prediction for the hypothetical proteins was done by using Bioinformatics web tools like CDD-BLAST, INTERPROSCAN, PFAM and COGs by searching protein databases for the presence of conserved domains. While tertiary structures were constructed using PS $^{2}$ Server- Protein Structure Prediction server. This study revealed presences of functional domain in 258 uncharacterized proteins. These deciphered enzymatic data for hypothetical proteins can be used for the understanding of functional, structural and evolutionary development of cyanophages and its life cycle along with their role in host evolution.
\end{abstract}

\section{Keywords}

Bioinformatics web tools, conserved domains, Protein structure prediction, uncharacterized proteins, life cycle.

\section{INTRODUCTION}

The cyanophages plays an important role in both horizontal gene transfer and host mortality of the microbial populations that are responsible for the biogeochemical processes that run the planet [5] [6] [13] [25] [27]. They shape the ecology and evolution of both [the host and the phage] over evolutionary time. However, we have only barely begun to understand the genomic repertoire of these important genetic vectors [6] [16]. More than $70 \%$ of sequenced bacterial genomes contain prophages [4] [7] [8]. They often represent the primary constituent of strain-to-strain variability [4] [20] [21] and their genes are among the most highly expressed genes in genomewide expression studies [22] [35]. The in-silico studies of hypothetical proteins (Uncharacterized proteins) for identifying their structure and function is an attempt to understand cyanophages and their role in cyanobacterial evolution [20] [33].

Computational biology assists us to predict the functionality in the uncharacterized sequences using the different strategies of comparative proteomics. The program's ability of homology searching using defined databases and by choosing standard parameters, the presence of the enzymatic conserved domain/s in the sequences could be searched out and it may assist in the categorizing protein into specific family [29] [32]. Bioinformatics web tools like CDDBLAST,INTERPROSCAN, PFAM and COGs can search the orthologous sequence in biological sequence databases for the target sequence, while assist in classification of target sequence in particular family [12] [26] [27] [28]. This study will helps us to understand the probable functions of hypothetical proteins in cyanophages. The online automated servers are available which can predict the three dimensional structures for protein sequences by using the strategy of aligning target sequences with orthologous sequences by virtue of sequence homology using best scored template of orthologous family member [30] [31]. Here, we have predicted 3-D structure using Protein Structure Prediction Server (PS ${ }^{2}$ server) [11] [37].

\section{MATERIALS AND METHODS}

\section{1 Sequence Retrieval}

The Complete protein sequences for 10 different cyanophages phages were downloaded from the Database of KEGG (http://www.genome.jp/kegg/). The phages under study includes Cyanophage PSS2 [24], Microcystis phage MaLMM01 [36], Prochlorococcus phage P-SSM2 [23], Prochlorococcus phage P-SSM4 [23], Prochlorococcus phage P-SSP7 [23], Synechococcus phage S-RSM4 [15], Synechococcus phage P60 [10], Synechococcus phage S-PM2 [14], Synechococcus phage syn9 [34] and Synechococcus phage Syn5 [17].

\section{2 Functional Annotations}

The hypothetical proteins from all 10 cyanophages were screened for the presence of conserved domains using the web-tools. The four bioinformatics web tools like CDDBLAST (http://www.ncbi.nlm.nih.gov/BLAST/) [2] [19] [3], INTERPROSCAN (http://www.abi.ac.uk/interpro) [38], Pfam (http://www.pfam.sanger.ac.uk/) [1] and COGs (http://www.ncbi.nih, gov/cog) [18] were used, which shows the ability to search the defined conserved domains in the sequences and assist in the classification of proteins in appropriate family. Hypothetical proteins analyzed by the function prediction web tools have shown variable results depending upon the information available in databases, when searched for the conserved domains in hypothetical sequences.

\section{3 Protein Structure Prediction}

Online PS ${ }^{2}$ Protein Structure Prediction Server was used to generate 3D-structures of hypothetical proteins 
(http://www.ps2.life.nctu.edu.tw/) [2] [9] [11] [19]. The server accepts the protein (query) sequences in FASTA format and uses the strategies of Pair-wise and multiple alignments to generate resultant proteins 3D structures, Which are constructed using structural positioning information of atomic coordinates for known template in PDB format using best scored alignment data. Where the selection of template was based on the same conserved domain detected in the functional annotations and which must be available in the structure alignment for modeling purpose.

\section{RESULT AND DISCUSSION}

The in silico structure and function of the cyanophages was done for 10 phages. The hypothetical proteins were classified by using sequence similarity search with close orthologous family members available in various protein databases using the web tools. The predictions of 3-D structures of protein were done by using online automated PS2 server. The analysis of hypothetical proteins of cyanophages for function annotations was done by using web tools for their classification into particular enzymatic family based on conserved domain available in the sequence which are represented in respective Table 1 through 10. From 10 different cyanophages, 258 hypothetical proteins were classified depending upon the presence of conserved domains. The (PS) ${ }^{2}$ Server built the three dimensional structures for 28 hypothetical proteins satisfactorily using best scored orthologous template. The 3-D structures built are represented sequentially in respective cyanophage specific gene. The templates with best scoring with hypothetical protein sequences are represented in the order as Template ID, Identity, Score and E-value which represented in structure column of each cyanophage analyzed. The structure and functional data for Cyanophage PSS2 (Table 1), Microcystis phage Ma-LMM01 (Table 2), Prochlorococcus phage PSSM2 (Table 3), Prochlorococcus phage P-SSM4 (Table 4), Prochlorococcus phage P-SSP7 (Table 5), Synechococcus phage S-RSM4 (Table 6), Synechococcus phage P60 (Table 7), Synechococcus phage S-PM2 (Table 8), Synechococcus phage syn9 (Table 9) and Synechococcus phage Syn5 (Table 10) are given in their respective tables.

Table 1 Structure and Functional Data for CYANOPHAGE PSS2

\begin{tabular}{|c|c|c|c|c|c|}
\hline NCBI Gene & CDD-Blast & Interproscan & pfam & COGs & Structures \\
\hline 8207392 & No & No & $\begin{array}{l}\text { mRNA_cap_C } \\
\text { mRNA capping } \\
\text { enzyme, C-terminal } \\
\text { domain }\end{array}$ & No & No \\
\hline 8207393 & No & No & $\begin{array}{l}\text { Predicted } \\
\text { transmembrane and } \\
\text { coiled-coil } 2 \text { protein }\end{array}$ & No & No \\
\hline 8207398 & No & No & Prefoldin subunit & No & No \\
\hline 8207408 & No & $\begin{array}{l}\text { Endodeoxyribonuclea } \\
\text { se, RusA-like }\end{array}$ & $\begin{array}{l}\text { RusA } \\
\text { Endodeoxyribonuclea } \\
\text { se RusA }\end{array}$ & No & $2 \mathrm{~h} 8 \mathrm{eA}-21-59-4 \mathrm{e}-10$ \\
\hline 8207411 & No & No & $\begin{array}{l}\text { Mec-17 Touch } \\
\text { receptor neuron } \\
\text { protein Mec-17 }\end{array}$ & No & No \\
\hline 8207412 & No & $\begin{array}{l}\text { Endodeoxyribonuclea } \\
\text { se, RusA-like }\end{array}$ & $\begin{array}{l}\text { RusA } \\
\text { Endodeoxyribonuclea } \\
\text { se RusA }\end{array}$ & No & $2 \mathrm{~h} 8 \mathrm{e} A-21-59-4 \mathrm{e}-10$ \\
\hline 8207413 & $\begin{array}{l}\text { HemN_C super } \\
\text { family[c106150], } \\
\text { Members of this } \\
\text { family are all oxygen- } \\
\text { independent } \\
\text { coproporphyrinogen- } \\
\text { III oxidases (HemN) }\end{array}$ & No & No & No & No \\
\hline 8207422 & No & No & $\begin{array}{l}\text { SDH_alpha Serine } \\
\text { dehydratase alpha } \\
\text { chain,Decorin_bind } \\
\text { Decorin binding } \\
\text { protein }\end{array}$ & No & No \\
\hline 8207426 & No & No & $\begin{array}{l}\text { SprT-like SprT-like } \\
\text { family }\end{array}$ & No & No \\
\hline 8207428 & No & No & $\begin{array}{l}\text { OEP Outer } \\
\text { membrane efflux } \\
\text { protein }\end{array}$ & No & No \\
\hline 8207436 & No & No & No & $\begin{array}{l}\text { COG0050 GTPases - } \\
\text { translation elongation } \\
\text { factors }\end{array}$ & 2 jesA -14 -42- 3e-06 \\
\hline 8207438 & No & No & RF-1 domain & No & No \\
\hline
\end{tabular}




\begin{tabular}{|c|c|c|c|c|c|}
\hline 8207450 & $\begin{array}{l}\text { FliI_clade3[TIGR034 } \\
\text { 98], flagellar protein } \\
\text { export ATPase FliI; } \\
\text { Members of this } \\
\text { protein family are the } \\
\text { FliI protein of } \\
\text { bacterial flagellum } \\
\text { systems }\end{array}$ & No & $\begin{array}{l}\text { Lac_bphage_repr } \\
\text { Lactococcus } \\
\text { bacteriophage } \\
\text { repressor }\end{array}$ & No & No \\
\hline 8207451 & No & No & $\begin{array}{l}\text { CBM_17_28 } \\
\text { Carbohydrate binding } \\
\text { domain }\end{array}$ & No & No \\
\hline 8207453 & No & No & $\begin{array}{l}\text { Activator_LAG-3 } \\
\text { Transcriptional } \\
\text { activator LAG-3 }\end{array}$ & No & No \\
\hline 8207461 & No & No & $\begin{array}{l}\text { SBP_bac_1 Bacterial } \\
\text { extracellular solute- } \\
\text { binding protein }\end{array}$ & No & No \\
\hline 8207472 & No & No & $\begin{array}{l}\text { Phage_tail_S Phage } \\
\text { virion morphogenesis } \\
\text { family }\end{array}$ & No & No \\
\hline 8207478 & No & $\begin{array}{l}\text { Fibritin/6- } \\
\text { phosphogluconate } \\
\text { dehydrogenase, C- } \\
\text { terminal extension }\end{array}$ & No & No & 1v1hA- 33- 36- 0.009 \\
\hline 8207485 & No & $\begin{array}{l}\text { Phage major tail } \\
\text { protein TP901-1 }\end{array}$ & No & No & No \\
\hline 8207493 & $\begin{array}{l}\text { HOOK protein; This } \\
\text { family consists of } \\
\text { several HOOK1, } 2 \\
\text { and } 3 \text { proteins from } \\
\text { different eukaryotic } \\
\text { organisms. }\end{array}$ & $\begin{array}{l}\text { Endothelin-like toxin, } \\
\text { conserved site, } \\
\text { Legume lectin, beta } \\
\text { chain, Mn/Ca-binding } \\
\text { site }\end{array}$ & No & No & No \\
\hline 8207500 & No & No & $\begin{array}{l}\text { Tail_tube Phage tail } \\
\text { tube protein }\end{array}$ & No & No \\
\hline 8207506 & No & NUMOD4 & NUMOD4 motif & No & No \\
\hline 8207507 & No & No & $\begin{array}{l}\text { HTH_8 Bacterial } \\
\text { regulatory protein, } \\
\text { Fis family, Putative } \\
\text { excisionase }\end{array}$ & No & No \\
\hline 8207510 & No & $\begin{array}{l}\text { Homeodomain- } \\
\text { related }\end{array}$ & $\begin{array}{l}\text { HTH_7 Helix-turn- } \\
\text { helix domain of } \\
\text { resolvase }\end{array}$ & No & \\
\hline
\end{tabular}

Table 2 Structure and Functional Data for MICROCYSTIS PHAGE MA-LMM01

\begin{tabular}{|c|c|c|c|c|c|}
\hline NCBI Gene & CDD-Blast & Interproscan & pfam & COGs & Structures \\
\hline 4484313 & No & LamB porin & No & No & \\
\hline 4484317 & $\begin{array}{l}\text { FGE-sulfatase super } \\
\text { family[cl00556], } \\
\text { Formylglycine- } \\
\text { generating sulfatase } \\
\text { enzyme }\end{array}$ & $\begin{array}{l}\text { Sulphatase-modifying } \\
\text { factor,C-type lectin } \\
\text { fold }\end{array}$ & $\begin{array}{l}\text { FGE-sulfatase } \\
\text { Formylglycine- } \\
\text { generating sulfatase } \\
\text { enzyme }\end{array}$ & No & $1 z 70 X-26-219-3 e-58$ \\
\hline 4484323 & $\begin{array}{l}\text { Peptidase M15, } \\
\text { PG_binding_1 super } \\
\text { family, Putative } \\
\text { peptidoglycan } \\
\text { binding domain }\end{array}$ & $\begin{array}{l}\text { Peptidoglycan } \\
\text { binding- } \\
\text { like,Hedgehog/DD- } \\
\text { peptidase, zinc- } \\
\text { binding motif, } \\
\text { Peptidase M15A, C- } \\
\text { terminal }\end{array}$ & $\begin{array}{l}\text { PG_binding_1 } \\
\text { Putative } \\
\text { peptidoglycan } \\
\text { binding domain } \\
\text {,Peptidase M15 }\end{array}$ & No & $11 \mathrm{buA}-23-145-7 \mathrm{e}-36$ \\
\hline 4484326 & No & No & $\begin{array}{l}\text { Curlin_rpt Curlin } \\
\text { associated repeat }\end{array}$ & No & No \\
\hline 4484330 & No & No & PAAR motif & No & No \\
\hline
\end{tabular}




\begin{tabular}{|c|c|c|c|c|c|}
\hline 4484331 & $\begin{array}{l}\text { FGE-sulfatase super } \\
\text { family, } \\
\text { Formylglycine- } \\
\text { generating sulfatase } \\
\text { enzyme }\end{array}$ & $\begin{array}{l}\text { Sulphatase-modifying } \\
\text { factor, C-type lectin } \\
\text { fold }\end{array}$ & $\begin{array}{l}\text { FGE-sulfatase } \\
\text { Formylglycine- } \\
\text { generating sulfatase } \\
\text { enzyme }\end{array}$ & No & $2 q 17 E-25-144-3 e-35$ \\
\hline 4484335 & No & $\begin{array}{l}\text { Concanavalin A-like } \\
\text { lectin/glucanase }\end{array}$ & No & No & 1a8dA- 12- 41- 4e-04 \\
\hline 4484337 & No & No & $\begin{array}{l}\text { Predicted RNA- } \\
\text { binding protein } \\
\text {,Probable } \\
\text { molybdopterin } \\
\text { binding } \\
\text { domain,Angiomotin } \\
\text { C terminal, RIM- } \\
\text { binding protein of the } \\
\text { cytomatrix active } \\
\text { zone, } \\
\text { Poly(hydroxyalcanoat } \\
\text { e) granule associated } \\
\text { protein (phasin) } \\
\text {,Autophagy protein } \\
\text { 16 } \\
\text { (ATG16),Tropomyosi } \\
\text { n,Biogenesis of } \\
\text { lysosome-related } \\
\text { organelles complex-1 } \\
\text { subunit } 2, \text { Phage } \\
\text { minor structural } \\
\text { protein GP20, Seryl- } \\
\text { tRNA synthetase N- } \\
\text { terminal domain, } \\
\text { TATA element } \\
\text { modulatory factor } 1 \\
\text { DNA binding,bZIP } \\
\text { transcription factor, } \\
\text { TSC-22/dip/bun } \\
\text { family, Axonemal } \\
\text { dynein light chain } \\
\text {,SNARE domain }\end{array}$ & No & No \\
\hline 4484338 & No & No & $\begin{array}{l}\text { RyR domain, } \\
\text { Oestrogen-responsive } \\
\text { protein Fam102A-B }\end{array}$ & No & No \\
\hline 4484339 & No & No & Sigma-70, region 4 & No & No \\
\hline 4484345 & No & HNH nuclease & HNH endonuclease & No & No \\
\hline 4484350 & No & Profilin/allergen & $\begin{array}{l}\text { ER protein Pkr1 } \\
\text {,PRA1 family protein }\end{array}$ & $\begin{array}{l}\text { NADH:ubiquinone } \\
\text { oxidoreductase } \\
\text { subunit } 5 \text { (chain } \\
\text { L)/Multisubunit } \\
\mathrm{Na} / \mathrm{H}+\text { antiporter, } \\
\text { MnhA subunit }\end{array}$ & No \\
\hline 4484351 & No & No & $\begin{array}{l}\text { TfoX N-terminal } \\
\text { domain }\end{array}$ & $\begin{array}{l}\text { Archaeal/vacuolar- } \\
\text { type H+-ATPase } \\
\text { subunit A }\end{array}$ & No \\
\hline 4484356 & $\begin{array}{l}\text { Baseplate_J super } \\
\text { family, Baseplate J- } \\
\text { like protein }\end{array}$ & $\begin{array}{l}\text { Baseplate assembly } \\
\text { protein J-like, } \\
\text { predicted }\end{array}$ & $\begin{array}{l}\text { Baseplate_J } \\
\text { Baseplate J-like } \\
\text { protein }\end{array}$ & No & No \\
\hline 4484376 & putative RNA ligase & No & No & No & No \\
\hline 4484378 & No & No & $\begin{array}{l}\text { RVT_2 Reverse } \\
\text { transcriptase (RNA- } \\
\text { dependent DNA } \\
\text { polymerase) }\end{array}$ & No & No \\
\hline 4484380 & No & No & KilA-N domain & No & No \\
\hline 4484383 & No & No & No & $\begin{array}{l}\text { Ribosomal protein } \\
\text { S12 }\end{array}$ & No \\
\hline 4484386 & No & No & NfeD-like & No & No \\
\hline 4484393 & No & No & $\begin{array}{l}\text { RINT-1 / TIP-1 } \\
\text { family }\end{array}$ & No & No \\
\hline 4484397 & No & No & NOGCT domain & No & No \\
\hline
\end{tabular}




\begin{tabular}{|c|c|c|c|c|c|}
\hline 4484398 & $\begin{array}{l}\text { Cas_Cas4 super } \\
\text { family,ATP- } \\
\text { dependent nuclease, } \\
\text { subunit B [DNA } \\
\text { replication, } \\
\text { recombination, and } \\
\text { repair] }\end{array}$ & $\begin{array}{l}\text { Restriction } \\
\text { endonuclease, type II- } \\
\text { like }\end{array}$ & No & No & 1w36B- 18-45-2e-05 \\
\hline 4484406 & No & No & $\begin{array}{l}\text { KGG Stress-induced } \\
\text { bacterial acidophilic } \\
\text { repeat motif }\end{array}$ & General stress protein & No \\
\hline 4484413 & No & No & $\begin{array}{l}\text { Ferric reductase } \\
\text { NAD binding domain }\end{array}$ & No & No \\
\hline 4484417 & No & No & $\begin{array}{l}\text { Proteobacterial lipase } \\
\text { chaperone protein }\end{array}$ & No & No \\
\hline 4484419 & No & No & Guanylate kinase & No & No \\
\hline 4484421 & No & No & LTXXQ motif & No & No \\
\hline 4484424 & No & No & $\begin{array}{l}\text { CTP synthase } \mathrm{N}- \\
\text { terminus }\end{array}$ & $\begin{array}{l}\text { CTP synthase (UTP- } \\
\text { ammonia lyase) }\end{array}$ & No \\
\hline 4484470 & No & No & $\begin{array}{l}\text { DNA polymerase III, } \\
\text { theta subunit }\end{array}$ & No & No \\
\hline 4484471 & No & No & Synapsin N-terminal & Ribonuclease HII & No \\
\hline 4484477 & No & PLD & No & $\begin{array}{l}\text { Methyl-accepting } \\
\text { chemotaxis protein }\end{array}$ & $\mathrm{NO}$ \\
\hline 4484479 & No & No & $\begin{array}{l}\mathrm{N} \text {-glycosylation } \\
\text { protein ,Predicted } \\
\text { membrane protein } \\
\text { (DUF2232) }\end{array}$ & No & NO \\
\hline 4484481 & No & $\begin{array}{l}\text { Zinc finger, SWIM- } \\
\text { type }\end{array}$ & SWIM zinc finger & No & NO \\
\hline
\end{tabular}

Table 3 Structure and Functional Data for PROCHLOROCOCCUS PHAGE P-SSM2

\begin{tabular}{|c|c|c|c|c|c|}
\hline NCBI Gene & CDD-Blast & Interproscan & pfam & COGs & Structures \\
\hline 3294165 & $\mathrm{NO}$ & $\mathrm{NO}$ & $\begin{array}{l}\text { Pestivirus NS3 } \\
\text { polyprotein peptidase } \\
\text { S31 }\end{array}$ & $\mathrm{NO}$ & $\mathrm{NO}$ \\
\hline 3294168 & NO & $\mathrm{NO}$ & $\begin{array}{l}\text { GSPII_E N-terminal } \\
\text { domain }\end{array}$ & $\mathrm{NO}$ & $\mathrm{NO}$ \\
\hline 3294169 & $\mathrm{NO}$ & NO & $\begin{array}{l}\text { GSPII_E N-terminal } \\
\text { domain }\end{array}$ & $\mathrm{NO}$ & $\mathrm{NO}$ \\
\hline 3294175 & $\mathrm{NO}$ & NO & $\begin{array}{l}\text { Serine dehydratase } \\
\text { alpha chain Fimbrial, } \\
\text { major and minor } \\
\text { subunit }\end{array}$ & $\mathrm{NO}$ & NO \\
\hline 3294185 & $\mathrm{NO}$ & $\mathrm{NO}$ & $\begin{array}{l}\text { Microtubule } \\
\text { associated } \\
\text {,Baculovirus LEF-11 } \\
\text { protein ,HECT- } \\
\text { domain (ubiquitin- } \\
\text { transferase),TATA- } \\
\text { binding protein } \\
\text { interacting (TIP20) }\end{array}$ & $\mathrm{NO}$ & NO \\
\hline$\underline{3294200}$ & $\mathrm{NO}$ & $\begin{array}{l}\text { Collagen triple helix } \\
\text { repeat }\end{array}$ & $\begin{array}{l}\text { Collagen triple helix } \\
\text { repeat ( } 20 \text { copies) } \\
\text {,Collagen triple helix } \\
\text { repeat ( } 20 \text { copies) }\end{array}$ & $\mathrm{NO}$ & $\mathrm{NO}$ \\
\hline 3294204 & $\mathrm{NO}$ & NO & $\begin{array}{l}\text { DNA circulation } \\
\text { protein N-terminus }\end{array}$ & $\mathrm{NO}$ & NO \\
\hline
\end{tabular}




\begin{tabular}{|c|c|c|c|c|c|}
\hline$\underline{3294217}$ & $\mathrm{NO}$ & $\mathrm{NO}$ & $\begin{array}{l}\text { Rab5 binding, } \\
\text { Fibrinogen alpha/beta } \\
\text { chain family,Flagella } \\
\text { accessory protein C } \\
\text { (FlaC), TATA } \\
\text { element modulatory } \\
\text { factor } 1 \text { TATA } \\
\text { binding, Spc24 } \\
\text { subunit of Ndc80 } \\
\text {,Septum formation } \\
\text { initiator, bZIP } \\
\text { transcription } \\
\text { factor,Herpesvirus } \\
\text { BLRF2 protein,Hr1 } \\
\text { repeat }\end{array}$ & $\mathrm{NO}$ & $\mathrm{NO}$ \\
\hline$\underline{3294225}$ & $\mathrm{NO}$ & $\begin{array}{l}\text { Collagen triple helix } \\
\text { repeat }\end{array}$ & $\begin{array}{l}\text { Collagen triple helix } \\
\text { repeat ( } 20 \text { copies) }\end{array}$ & $\mathrm{NO}$ & $\mathrm{NO}$ \\
\hline$\underline{3294229}$ & $\mathrm{NO}$ & $\mathrm{NO}$ & BMC domain & $\mathrm{NO}$ & NO \\
\hline$\underline{3294232}$ & $\mathrm{NO}$ & NO & $\begin{array}{l}\text { Ribosomal protein } \\
\text { S27 } \\
\text {,Desulfoferrodoxin, } \\
\text { N-terminal domain }\end{array}$ & $\mathrm{NO}$ & NO \\
\hline 3294245 & NO & NO & $\begin{array}{l}\text { S-adenosyl-L- } \\
\text { homocysteine } \\
\text { hydrolase, NAD } \\
\text { binding domain ,EF } \\
\text { hand associated }\end{array}$ & NO & NO \\
\hline$\underline{3294251}$ & $\mathrm{NO}$ & $\mathrm{NO}$ & $\begin{array}{l}\text { Selenium binding } \\
\text { protein, Fumarate } \\
\text { reductase subunit D }\end{array}$ & $\begin{array}{l}\text { Ribosome recycling } \\
\text { factor }\end{array}$ & NO \\
\hline 3294254 & NO & NO & $\begin{array}{l}\text { FerA (NUC095) } \\
\text { domain }\end{array}$ & NO & NO \\
\hline$\underline{3294255}$ & NO & NO & $\begin{array}{l}\text { Acetyl co-enzyme A } \\
\text { carboxylase } \\
\text { carboxyltransferase } \\
\text { alpha subunit } \\
\text {,emp24/gp25L/p24 } \\
\text { family/GOLD } \\
\text {,Flagella accessory } \\
\text { protein C (FlaC), } \\
\text { Trimeric coiled-coil } \\
\text { oligomerisation } \\
\text { domain of matrilin, } \\
\text { Tetrahydromethanopt } \\
\text { erin S- } \\
\text { methyltransferase, } \\
\text { subunit G Bacillus } \\
\text { transposase protein } \\
\text { Mating-type protein } \\
\text { MAT alpha 1 }\end{array}$ & $\begin{array}{l}\text { ATPase involved in } \\
\text { DNA repair }\end{array}$ & NO \\
\hline$\underline{3294256}$ & $\mathrm{NO}$ & NO & $\begin{array}{l}\text { Borrelia burgdorferi } \\
\text { BBR25 lipoprotein }\end{array}$ & $\mathrm{NO}$ & NO \\
\hline$\underline{3294268}$ & $\mathrm{NO}$ & $\mathrm{NO}$ & $\mathrm{NO}$ & $\begin{array}{l}\text { Acyl-CoA } \\
\text { synthetases (AMP- } \\
\text { forming)/AMP-acid } \\
\text { ligases II }\end{array}$ & NO \\
\hline$\underline{3294276}$ & $\mathrm{NO}$ & NO & $\begin{array}{l}\text { Chitin binding } \\
\text { Peritrophin-A domain } \\
\text {, Glycine rich protein } \\
\text { family }\end{array}$ & $\mathrm{NO}$ & NO \\
\hline$\underline{3294280}$ & $\mathrm{NO}$ & NO & $\begin{array}{l}\text { C3 binding domain } 4 \\
\text { of IgG-bind protein } \\
\text { SBI }\end{array}$ & $\mathrm{NO}$ & NO \\
\hline$\underline{3294282}$ & $\mathrm{NO}$ & $\mathrm{NO}$ & $\begin{array}{l}\text { Sigma-54 factor, core } \\
\text { binding domain }\end{array}$ & $\mathrm{NO}$ & $\mathrm{NO}$ \\
\hline$\underline{3294285}$ & $\mathrm{NO}$ & $\mathrm{NO}$ & $\begin{array}{l}\text { Apolipophorin-III } \\
\text { precursor (apoLp-III) }\end{array}$ & $\mathrm{NO}$ & 1dlcA-18- 31- 0.007 \\
\hline
\end{tabular}




\begin{tabular}{|c|c|c|c|c|c|}
\hline$\underline{3294288}$ & $\mathrm{NO}$ & $\mathrm{NO}$ & $\begin{array}{l}\text { Predicted coiled-coil } \\
\text { domain-containing } \\
\text { protein (DUF2360) }\end{array}$ & NO & 1y0eA- $24-38-0.003$ \\
\hline$\underline{3294297}$ & NO & $\mathrm{NO}$ & $\begin{array}{l}\text { Phage antitermination } \\
\text { protein Q }\end{array}$ & NO & $\mathrm{NO}$ \\
\hline$\underline{3294305}$ & $\mathrm{NO}$ & $\mathrm{NO}$ & $\begin{array}{l}\text { IRSp53/MIM } \\
\text { homology domain } \\
\text {,Intermediate filament } \\
\text { protein ,NUDE } \\
\text { protein, C-terminal } \\
\text { conserved region } \\
\text {,Fibrinogen } \\
\text { alpha/beta chain } \\
\text { family,fzo-like } \\
\text { conserved region } \\
\text {,IncA protein } \\
\text {,Mitochondrial } \\
\text { ATPase inhibitor, } \\
\text { IATP, Outer } \\
\text { membrane protein } \\
\text { (OmpH-like) }\end{array}$ & $\mathrm{NO}$ & 2 dfsA -36 -34- 0.005 \\
\hline$\underline{3294306}$ & NO & NO & $\begin{array}{l}\text { Collagen triple helix } \\
\text { repeat ( } 20 \text { copies })\end{array}$ & $\mathrm{NO}$ & NO \\
\hline$\underline{3294325}$ & NO & NO & $\begin{array}{l}\text { FERM central } \\
\text { domain }\end{array}$ & $\mathrm{NO}$ & $\mathrm{NO}$ \\
\hline$\underline{3294333}$ & $\mathrm{NO}$ & $\begin{array}{l}\text { Parallel beta-helix } \\
\text { repeat }\end{array}$ & $\begin{array}{l}\text { Collagen triple helix } \\
\text { repeat ( } 20 \text { copies })\end{array}$ & $\mathrm{NO}$ & NO \\
\hline$\underline{3294334}$ & $\mathrm{NO}$ & NO & $\begin{array}{l}\text { R67 dihydrofolate } \\
\text { reductase }\end{array}$ & $\mathrm{NO}$ & 1cygA -13 -30 -0.009 \\
\hline$\underline{3294345}$ & $\mathrm{NO}$ & $\mathrm{NO}$ & HEPN domain & $\mathrm{NO}$ & $\mathrm{NO}$ \\
\hline$\underline{3294350}$ & $\mathrm{NO}$ & HNH nuclease & $\begin{array}{l}\text { YvbH-like } \\
\text { oligomerisation } \\
\text { region, Putative } \\
\text { GTPase activating } \\
\text { protein for Arf , HNH } \\
\text { endonuclease, GrpE }\end{array}$ & $\mathrm{NO}$ & $\mathrm{NO}$ \\
\hline$\underline{3294355}$ & $\mathrm{NO}$ & $\mathrm{NO}$ & Zinc ribbon domain & $\mathrm{NO}$ & NO \\
\hline$\underline{3294365}$ & $\mathrm{NO}$ & NO & $\begin{array}{l}\text { Conserved mid region } \\
\text { of cactin }\end{array}$ & NO & NO \\
\hline$\underline{3294370}$ & $\mathrm{NO}$ & $\mathrm{NO}$ & mbt repeat & $\mathrm{NO}$ & $\mathrm{NO}$ \\
\hline$\underline{3294374}$ & $\mathrm{NO}$ & $\mathrm{NO}$ & $\begin{array}{l}\text { PDZ domain (Also } \\
\text { known as DHR or } \\
\text { GLGF) }\end{array}$ & NO & NO \\
\hline$\underline{3294379}$ & $\mathrm{NO}$ & $\mathrm{NO}$ & RHS Repeat & $\mathrm{NO}$ & NO \\
\hline$\underline{3294386}$ & $\mathrm{NO}$ & $\begin{array}{l}\text { DNA methylase, N-6 } \\
\text { adenine-specific, } \\
\text { conserved site }\end{array}$ & $\begin{array}{l}\text { Eco57I restriction } \\
\text { endonuclease }\end{array}$ & $\mathrm{NO}$ & NO \\
\hline$\underline{3294394}$ & $\mathrm{NO}$ & $\mathrm{NO}$ & $\begin{array}{l}\text { yrrolo-quinoline } \\
\text { quinone coenzyme C- } \\
\text { terminus }\end{array}$ & $\mathrm{NO}$ & $\mathrm{NO}$ \\
\hline$\underline{3294396}$ & $\mathrm{NO}$ & NO & $\begin{array}{l}\text { Motilin/ghrelin- } \\
\text { associated peptide, } \\
\text { Phage Mu protein F } \\
\text { like protein }\end{array}$ & NO & NO \\
\hline$\underline{3294410}$ & $\mathrm{NO}$ & NO & $\begin{array}{l}\text { Multicopper oxidase, } \\
\text { AraC-like ligand } \\
\text { binding domain }\end{array}$ & $\mathrm{NO}$ & $2 \mathrm{hbtA}-17-38-0.002$ \\
\hline$\underline{3294422}$ & NO & NO & VPS28 protein & $\mathrm{NO}$ & NO \\
\hline$\underline{3294425}$ & $\mathrm{NO}$ & $\mathrm{NO}$ & PPP4R2 & $\mathrm{NO}$ & NO \\
\hline$\underline{3294426}$ & $\mathrm{NO}$ & $\mathrm{NO}$ & $\begin{array}{l}\text { Thrombin inhibitor } \\
\text { from mosquito }\end{array}$ & $\mathrm{NO}$ & NO \\
\hline$\underline{3294446}$ & $\mathrm{NO}$ & NO & $\begin{array}{l}\text { Spherical virus-type } \\
\text { peptidase }\end{array}$ & NO & NO \\
\hline$\underline{3294461}$ & NO & NO & $\begin{array}{l}\text { SprT-like family } \\
\end{array}$ & NO & NO \\
\hline
\end{tabular}




\begin{tabular}{|c|c|c|c|c|c|}
\hline 3294467 & NO & NO & $\begin{array}{l}\text { Herpesvirus UL4 } \\
\text { family }\end{array}$ & NO & $\mathrm{NO}$ \\
\hline$\underline{3294469}$ & NO & Photosystem II PsbN & $\begin{array}{l}\text { Photosystem II } \\
\text { reaction centre } \mathrm{N} \\
\text { protein }(\mathrm{psbN})\end{array}$ & NO & $\mathrm{NO}$ \\
\hline$\underline{3294473}$ & NO & $\mathrm{NO}$ & $\begin{array}{l}\text { Invariant surface } \\
\text { glycoprotein }\end{array}$ & NO & $\mathrm{NO}$ \\
\hline$\underline{3294478}$ & NO & NO & $\begin{array}{l}\text { Mediator complex } \\
\text { subunit } 28 \text {,SlyX }\end{array}$ & NO & $\mathrm{NO}$ \\
\hline 3294494 & NO & NO & $\begin{array}{l}\text { OMS28 porin , } \\
\text { Transcription } \\
\text { factor/nuclear export } \\
\text { subunit protein } 2 \\
\text {,Microtubule } \\
\text { associated, Golgi } \\
\text { transport complex } \\
\text { subunit } 5 \text {,Erp protein } \\
\text { C-terminus, Septum } \\
\text { formation initiator } \\
\text {,Vesicle transport v- } \\
\text { SNARE protein N- } \\
\text { terminus ,Heat shock } \\
\text { factor binding protein } \\
1\end{array}$ & NO & $\mathrm{NO}$ \\
\hline
\end{tabular}

Table 4 Structure and Functional Data for PROCHLOROCOCCUS PHAGE P-SSM4

\begin{tabular}{|c|c|c|c|c|c|}
\hline NCBI Gene & CDD-Blast & Interproscan & pfam & COGs & Structures \\
\hline 10021827 & $\mathrm{NO}$ & NO & Lipase (class 2) & NO & NO \\
\hline$\underline{10021830}$ & NO & Photosystem II PsbN & $\begin{array}{l}\text { Photosystem II } \\
\text { reaction centre N } \\
\text { protein }(\mathrm{psbN}) \\
\text {,NADH } \\
\text { dehydrogenase } \\
\text { subunit } 5 \text { C-terminus }\end{array}$ & NO & NO \\
\hline 10021841 & $\mathrm{NO}$ & $\mathrm{NO}$ & $\begin{array}{l}\text { Syntaxin } 6, \mathrm{~N}- \\
\text { terminal }\end{array}$ & $\mathrm{NO}$ & NO \\
\hline 10021846 & NO & NO & $\begin{array}{l}\text { Lecithin:cholesterol } \\
\text { acyltransferase }\end{array}$ & NO & NO \\
\hline$\underline{10021847}$ & $\mathrm{NO}$ & $\mathrm{NO}$ & $\begin{array}{l}\text { Zinc finger C-x8-C- } \\
\text { x5-C-x3-H type (and } \\
\text { similar) }\end{array}$ & $\mathrm{NO}$ & $\mathrm{NO}$ \\
\hline$\underline{3294505}$ & NO & NO & $\begin{array}{l}\text { Nuclear fragile } X \\
\text { mental retardation- } \\
\text { interacting protein } 1 \\
\text { (NUFIP1) }\end{array}$ & $\mathrm{NO}$ & NO \\
\hline$\underline{3294509}$ & $\mathrm{NO}$ & $\mathrm{NO}$ & $\begin{array}{l}\text { RST domain of plant } \\
\text { C-terminal , Hr1 } \\
\text { repeat }\end{array}$ & $\mathrm{NO}$ & $\mathrm{NO}$ \\
\hline$\underline{3294513}$ & $\mathrm{NO}$ & NO & $\begin{array}{l}\text { Mitochondrial } \\
\text { glycoprotein } \\
\text {,Staphylococcal } \\
\text { complement inhibitor } \\
\text { SCIN ,Bacteriophage } \\
\text { FRD3 protein }\end{array}$ & $\mathrm{NO}$ & NO \\
\hline$\underline{3294514}$ & NO & NO & $\begin{array}{l}\text { Macrophage } \\
\text { scavenger receptor }\end{array}$ & NO & NO \\
\hline$\underline{3294516}$ & $\mathrm{NO}$ & $\mathrm{NO}$ & $\begin{array}{l}\text { Respiratory-chain } \\
\text { NADH } \\
\text { dehydrogenase } 24 \mathrm{Kd} \\
\text { subunit }\end{array}$ & $\mathrm{NO}$ & $\mathrm{NO}$ \\
\hline$\underline{3294520}$ & NO & NO & $\begin{array}{l}\text { N-acetylmuramoyl-L- } \\
\text { alanine amidase }\end{array}$ & $\mathrm{NO}$ & NO \\
\hline$\underline{3294525}$ & $\mathrm{NO}$ & NO & $\begin{array}{l}\text { Spc7 kinetochore } \\
\text { protein }\end{array}$ & NO & NO \\
\hline 3294527 & NO & NO & $\begin{array}{l}\text { Carbohydrate binding } \\
\text { domain }\end{array}$ & NO & 1 guiA $-16-39-0.002$ \\
\hline
\end{tabular}




\begin{tabular}{|c|c|c|c|c|c|}
\hline$\underline{3294542}$ & NO & $\mathrm{NO}$ & $\begin{array}{l}\text { Protein phosphatase } \\
\text { 2A regulatory B } \\
\text { subunit (B56 family) }\end{array}$ & $\mathrm{NO}$ & $\mathrm{NO}$ \\
\hline$\underline{3294543}$ & NO & NO & $\begin{array}{l}\text { Ezrin/radixin/moesin } \\
\text { family, Clusterin- } \\
\text { associated protein-1 }\end{array}$ & NO & NO \\
\hline$\underline{3294564}$ & NO & NO & $\begin{array}{l}\text { Type I restriction and } \\
\text { modification enzyme } \\
\text { - subunit R C } \\
\text { terminal }\end{array}$ & NO & NO \\
\hline$\underline{3294567}$ & $\mathrm{NO}$ & $\mathrm{NO}$ & $\begin{array}{l}\text { Preprotein translocase } \\
\text { SecG subunit }\end{array}$ & $\mathrm{NO}$ & $\mathrm{NO}$ \\
\hline$\underline{3294590}$ & $\mathrm{NO}$ & NO & $\begin{array}{l}\text { Mitochondrial } \\
\text { ribosomal protein } \\
\text { L28 }\end{array}$ & $\mathrm{NO}$ & NO \\
\hline$\underline{3294613}$ & NO & NO & $\begin{array}{l}\text { Orbivirus outer } \\
\text { capsid protein VP2 } \\
\text {,RNA polymerase } \\
\text { recycling family C- } \\
\text { terminal }\end{array}$ & $\mathrm{NO}$ & $\mathrm{NO}$ \\
\hline$\underline{3294614}$ & NO & NO & $\begin{array}{l}\text { Chordopoxvirus } \\
\text { fusion protein } \\
\text {,Resolvase, } \mathrm{N} \\
\text { terminal domain }\end{array}$ & NO & NO \\
\hline$\underline{3294634}$ & $\mathrm{NO}$ & $\begin{array}{l}\text { Fibrinogen, } \\
\text { alpha/beta/gamma } \\
\text { chain, C-terminal } \\
\text { globular }\end{array}$ & $\begin{array}{l}\text { FadR C-terminal } \\
\text { domain }\end{array}$ & $\mathrm{NO}$ & 1 fzcB $-23-44-4 \mathrm{e}-05$ \\
\hline$\underline{3294636}$ & $\mathrm{NO}$ & $\mathrm{NO}$ & $\begin{array}{l}\text { bZIP transcription } \\
\text { factor, WW domain } \\
\text { binding protein } 11\end{array}$ & $\mathrm{NO}$ & $\mathrm{NO}$ \\
\hline$\underline{3294655}$ & $\mathrm{NO}$ & $\mathrm{NO}$ & NO & $\begin{array}{l}\text { Translation initiation } \\
\text { factor } 2 \text { (GTPase) }\end{array}$ & NO \\
\hline$\underline{3294670}$ & NO & NO & $\begin{array}{l}\text { BOP1NT (NUC169) } \\
\text { domain }\end{array}$ & NO & NO \\
\hline$\underline{3294673}$ & NO & $\mathrm{NO}$ & $\begin{array}{l}\text { STAT1 TAZ2 } \\
\text { binding domain }\end{array}$ & $\begin{array}{l}\text { ATPase involved in } \\
\text { DNA repair }\end{array}$ & NO \\
\hline 3294682 & NO & NO & $\begin{array}{l}\text { T4-like virus tail } \\
\text { tube protein gp19 }\end{array}$ & NO & NO \\
\hline$\underline{3294691}$ & NO & NO & $\begin{array}{l}\text { Phage regulatory } \\
\text { protein Rha } \\
\text { (Phage_pRha) }\end{array}$ & NO & NO \\
\hline
\end{tabular}

Table 5 Structure and Functional Data for PROCHLOROCOCCUS PHAGE P-SSP7

\begin{tabular}{|l|l|l|l|l|l|}
\hline NCBI Gene & CDD-Blast & Interproscan & pfam & COGs & Structures \\
\hline$\underline{3294704}$ & NO & NO & MutS domain III & NO & NO \\
\hline$\underline{3294712}$ & NO & NO & $\begin{array}{l}\text { S- } \\
\text { adenosylmethionine } \\
\text { synthetase }\end{array}$ & NO \\
\hline$\underline{3294713}$ & NO & NO & YvrJ protein family & & NO \\
\hline$\underline{3294721}$ & NO & NO & $\begin{array}{l}\text { HicB family } \\
\text { Nolyketide synthesis } \\
\text { cyclase, Ubiquitin- } \\
\text { specific protease 7 }\end{array}$ & NO & NO \\
\hline$\underline{3294725}$ & NO & $\begin{array}{l}\text { Chitin synthesis } \\
\text { regulation, resistance } \\
\text { to Congo red }\end{array}$ & NO & NO & NO \\
\hline
\end{tabular}




\begin{tabular}{|l|l|l|l|l|l|}
\hline$\underline{3294726}$ & NO & $\begin{array}{l}\text { Winged helix-turn- } \\
\text { helix transcription } \\
\text { repressor DNA- } \\
\text { binding }\end{array}$ & NO & NO & NO \\
\hline$\underline{3294728}$ & NO & NO & $\begin{array}{l}\text { Phycobilisome } \\
\text { degradation protein } \\
\text { nblA }\end{array}$ & NO & NO \\
\hline$\underline{3294735}$ & NO & NO & ERF superfamily & NO & NO \\
\hline
\end{tabular}

Table 6 Structure and Functional Data for SYNECHOCOCCUS PHAGE S-RSM4

\begin{tabular}{|c|c|c|c|c|c|}
\hline NCBI Gene & CDD-Blast & Interproscan & pfam & COGs & Structures \\
\hline$\underline{8303263}$ & NO & NO & $\begin{array}{l}\text { Coatomer (COPI) } \\
\text { alpha subunit C- } \\
\text { terminus }\end{array}$ & $\mathrm{NO}$ & NO \\
\hline$\underline{8303264}$ & NO & $\mathrm{NO}$ & $\begin{array}{l}\text { Restriction } \\
\text { endonuclease EcoRV }\end{array}$ & $\mathrm{NO}$ & NO \\
\hline$\underline{8303265}$ & $\mathrm{NO}$ & $\mathrm{NO}$ & $\begin{array}{l}\text { Herpesvirus UL87 } \\
\text { family }\end{array}$ & $\mathrm{NO}$ & $\mathrm{NO}$ \\
\hline$\underline{8303268}$ & $\mathrm{NO}$ & Thioredoxin fold & $\mathrm{NO}$ & $\mathrm{NO}$ & $\mathrm{NO}$ \\
\hline$\underline{8303284}$ & NO & NO & CARDB & NO & NO \\
\hline 8303289 & NO & $\begin{array}{l}\text { Prevent-host-death } \\
\text { protein }\end{array}$ & Phd_YefM & NO & $2 \mathrm{a} 6 \mathrm{qB}-26-34-0.008$ \\
\hline$\underline{8303293}$ & $\mathrm{NO}$ & $\mathrm{NO}$ & $\begin{array}{l}\text { GIY-YIG catalytic } \\
\text { domain }\end{array}$ & $\mathrm{NO}$ & NO \\
\hline$\underline{8303304}$ & NO & NO & $\begin{array}{l}\text { Prolyl 4-Hydroxylase } \\
\text { alpha-subunit, } \mathrm{N} \text { - } \\
\text { terminal region }\end{array}$ & $\mathrm{NO}$ & NO \\
\hline 8303326 & NO & $\mathrm{NO}$ & $\begin{array}{l}\text { Formiminotransferase } \\
\text { domain, N-terminal } \\
\text { subdomain }\end{array}$ & $\mathrm{NO}$ & NO \\
\hline 8303337 & $\mathrm{NO}$ & $\mathrm{NO}$ & $\begin{array}{l}\text { BPS (Between PH } \\
\text { and SH2) }\end{array}$ & $\mathrm{NO}$ & NO \\
\hline$\underline{8303341}$ & NO & NO & Glycine rich protein & $\mathrm{NO}$ & NO \\
\hline$\underline{8303342}$ & NO & $\mathrm{NO}$ & $\begin{array}{l}\text { Phytanoyl-CoA } \\
\text { dioxygenase (PhyH) }\end{array}$ & $\mathrm{NO}$ & $2 \mathrm{fcuA}-11-38-0.002$ \\
\hline$\underline{8303353}$ & NO & $\mathrm{NO}$ & $\begin{array}{l}\text { Bacterial-like globin } \\
\text {,Major Outer Sheath } \\
\text { Protein C-terminal } \\
\text { region }\end{array}$ & $\mathrm{NO}$ & NO \\
\hline 8303371 & $\mathrm{NO}$ & $\mathrm{NO}$ & $\begin{array}{l}\text { NusA N-terminal } \\
\text { domain }\end{array}$ & $\mathrm{NO}$ & NO \\
\hline$\underline{8303376}$ & $\mathrm{NO}$ & $\mathrm{NO}$ & $\begin{array}{l}\text { Transposase family } \\
\text { tnp2, Associated with } \\
\text { zinc fingers }\end{array}$ & $\mathrm{NO}$ & NO \\
\hline$\underline{8303378}$ & NO & NO & $\begin{array}{l}\text { T4 bacteriophage } \\
\text { base plate protein }\end{array}$ & $\mathrm{NO}$ & NO \\
\hline$\underline{8303382}$ & NO & $\begin{array}{l}\text { Transcription } \\
\text { regulator } \\
\text { AbrB/SpoV, } \\
\text { predicted } \\
\end{array}$ & $\begin{array}{l}\text { SpoVT / AbrB like } \\
\text { domain }\end{array}$ & $\mathrm{NO}$ & NO \\
\hline
\end{tabular}




\begin{tabular}{|c|c|c|c|c|c|}
\hline$\underline{8303383}$ & $\mathrm{NO}$ & NO & $\begin{array}{l}\text { SF-assemblin/beta } \\
\text { giardin, } \\
\text { Endoribonuclease } \\
\text { XendoU, Colicin } \\
\text { immunity protein / } \\
\text { pyocin immunity } \\
\text { protein, Phage capsid } \\
\text { scaffolding protein } \\
\text { (GPO) serine } \\
\text { peptidase,Serpin } \\
\text { (serine protease } \\
\text { inhibitor),Biofilm } \\
\text { formation regulator } \\
\text { YbaJ, UDP- } \\
\text { glucose/GDP- } \\
\text { mannose } \\
\text { dehydrogenase } \\
\text { family, central } \\
\text { domain }\end{array}$ & NO & NO \\
\hline$\underline{8303389}$ & $\mathrm{NO}$ & NO & $\begin{array}{l}\text { Inorganic } \\
\text { pyrophosphatase }\end{array}$ & $\mathrm{NO}$ & $\mathrm{NO}$ \\
\hline$\underline{8303391}$ & $\mathrm{NO}$ & NO & YebG protein & $\mathrm{NO}$ & NO \\
\hline$\underline{8303393}$ & NO & NO & $\begin{array}{l}\text { Ribulose } \\
\text { bisphosphate } \\
\text { carboxylase large } \\
\text { chain, N-terminal } \\
\text { domain }\end{array}$ & NO & NO \\
\hline 8303394 & NO & NO & $\begin{array}{l}\text { Peptidase propeptide } \\
\text { and YPEB domain }\end{array}$ & NO & NO \\
\hline$\underline{8303395}$ & $\mathrm{NO}$ & NO & $\begin{array}{l}\text { RED-like protein N- } \\
\text { terminal region }\end{array}$ & $\mathrm{NO}$ & NO \\
\hline$\underline{8303397}$ & NO & $\mathrm{NO}$ & $\begin{array}{l}\text { RmlD substrate } \\
\text { binding domain }\end{array}$ & $\mathrm{NO}$ & NO \\
\hline$\underline{8303401}$ & $\mathrm{NO}$ & $\mathrm{NO}$ & $\begin{array}{l}\text { Eco57I restriction- } \\
\text { modification } \\
\text { methylase }\end{array}$ & $\mathrm{NO}$ & \\
\hline$\underline{8303402}$ & $\mathrm{NO}$ & SP1917 domain & $\begin{array}{l}\text { C-5 cytosine-specific } \\
\text { DNA methylase } \\
\text {,Hydrolytic ATP } \\
\text { binding site of dynein } \\
\text { motor region D1 }\end{array}$ & $\mathrm{NO}$ & NO \\
\hline$\underline{8303406}$ & NO & NO & $\begin{array}{l}\text { Alpha and gamma } \\
\text { adaptin binding } \\
\text { protein p34 } \\
\text {,Autophagy protein } \\
\text { Apg6, MbeD/MobD } \\
\text { like, MerR, DNA } \\
\text { binding, Haemolysin } \\
\text { XhlA, FlgN protein, } \\
\text { WW domain binding } \\
\text { protein } 11\end{array}$ & NO & NO \\
\hline$\underline{8303408}$ & NO & $\mathrm{NO}$ & $\begin{array}{l}\text { WASP-binding } \\
\text { domain of Sorting } \\
\text { nexin protein }\end{array}$ & $\mathrm{NO}$ & $\mathrm{NO}$ \\
\hline$\underline{8303425}$ & NO & $\mathrm{NO}$ & WSK motif & $\mathrm{NO}$ & NO \\
\hline$\underline{8303428}$ & NO & $\mathrm{NO}$ & 3D domain & $\mathrm{NO}$ & NO \\
\hline 8303442 & NO & NO & Rubredoxin & $\mathrm{NO}$ & $3 \mathrm{ct} 5 \mathrm{~A}-19-81-2 \mathrm{e}-16$ \\
\hline 8303451 & NO & $\mathrm{NO}$ & $\begin{array}{l}\text { GnsA/GnsB family } \\
\text {,Calcium binding and } \\
\text { coiled-coil domain } \\
\text { (CALCOCO1) like, } \\
\text { Mitochondrial } \\
\text { ATPase inhibitor, } \\
\text { IATP,Herpesvirus } \\
\text { UL14-like protein, } \\
\text { IncA protein }\end{array}$ & $\mathrm{NO}$ & $\mathrm{NO}$ \\
\hline$\underline{8303463}$ & NO & NO & $\begin{array}{l}\text { Gryzun, putative } \\
\text { Golgi trafficking }\end{array}$ & NO & $\mathrm{NO}$ \\
\hline
\end{tabular}




\begin{tabular}{|l|l|l|l|l|l|}
\hline$\underline{8303464}$ & NO & NO & $\begin{array}{l}\text { T4-like virus tail tube } \\
\text { protein gp19 }\end{array}$ & NO & NO \\
\hline$\underline{8303480}$ & NO & NO & $\begin{array}{l}\text { Glycosylphosphatidyl } \\
\text { inositol-anchored } \\
\text { merozoite surface } \\
\text { protein, Secretion } \\
\text { system effector C } \\
\text { (SseC) like family, } \\
\text { FAD binding domain } \\
\text { in molybdopterin } \\
\text { dehydrogenase }\end{array}$ & $\begin{array}{l}\text { NO } \\
\text { hydronenase large } \\
\text { subunit, C-terminal } \\
\text { domain }\end{array}$ & NO \\
\hline$\underline{8303493}$ & NO & NO & $\begin{array}{l}\text { Heat-labile } \\
\text { enterotoxin beta chain }\end{array}$ & NO & NO \\
\hline$\underline{8303499}$ & NO & NO & $\begin{array}{l}\text { Calponin homology } \\
\text { (CH) domain }\end{array}$ & NO & NO \\
\hline$\underline{8303501}$ & NO & NO & $\begin{array}{l}\text { Cell division } \\
\text { inhibitor SulA }\end{array}$ & NO & NO \\
\hline$\underline{8303503}$ & NO & NO & & \\
\hline
\end{tabular}

Table 7 Structure and Functional Data for SYNECHOCOCCUS PHAGE P60

\begin{tabular}{|l|l|l|l|l|l|}
\hline NCBI Gene & CDD-Blast & Interproscan & pfam & COGs & Structures \\
\hline$\underline{932709}$ & NO & NO & $\begin{array}{l}\text { GspL periplasmic } \\
\text { domain }\end{array}$ & NO & NO \\
\hline$\underline{932720}$ & NO & $\begin{array}{l}\text { Glycosylphosphatidyl } \\
\text { inositol-anchored } \\
\text { merozoite surface } \\
\text { protein , Peptidase } \\
\text { inhibitor I78 family }\end{array}$ & NO & NO \\
\hline$\underline{932725}$ & NO & NO & $\begin{array}{l}\text { GspL periplasmic } \\
\text { domain }\end{array}$ & NO & NO \\
\hline$\underline{932740}$ & NO & $\begin{array}{l}\text { TNF(Tumour } \\
\text { Necrosis Factor) } \\
\text { family }\end{array}$ & NO & NO \\
\hline$\underline{932761}$ & NO & NO & $\begin{array}{l}\text { Occludin homology } \\
\text { domain }\end{array}$ & NO & NO \\
\hline 932783 & $\begin{array}{l}\text { Type III secretion } \\
\text { protein (HpaP) } \\
\text { Down syndrome cell } \\
\text { adhesion molecule C } \\
\text { terminal , Major } \\
\text { surface antigen from } \\
\text { hepadnavirus }\end{array}$ & NO & NO \\
\hline
\end{tabular}

Table 8 Structure and Functional Data for SYNECHOCOCCUS PHAGE S-PM2

\begin{tabular}{|l|l|l|l|l|l|}
\hline NCBI Gene & CDD-Blast & Interproscan & pfam & COGs & Structures \\
\hline$\underline{3260259}$ & NO & NO & CBP4 & NO & NO \\
\hline$\underline{3260265}$ & NO & NO & $\begin{array}{l}\text { Phage antitermination } \\
\text { protein Q }\end{array}$ & NO & NO \\
\hline$\underline{3260269}$ & NO & $\begin{array}{l}\text { Tetrahydromethanopt } \\
\text { erin S- } \\
\text { methyltransferase, } \\
\text { subunit G ,Spc24 } \\
\text { subunit of Ndc80, } \\
\text { Proteins of 100 } \\
\text { residues with WXG, } \\
\text { Flagella accessory } \\
\text { protein C (FlaC) }\end{array}$ & NO & 1 f6wA- 35- 35-0.003 \\
\hline
\end{tabular}




\begin{tabular}{|c|c|c|c|c|c|}
\hline 3260271 & $\mathrm{NO}$ & NO & $\begin{array}{l}\text { Thermoplasma } \\
\text { acidophilum protein } \\
\text { TA0956 }\end{array}$ & NO & NO \\
\hline 3260279 & $\mathrm{NO}$ & NO & $\begin{array}{l}\text { Prominin , DASH } \\
\text { complex subunit } \\
\text { Dad2, Predicted } \\
\text { SPOUT } \\
\text { methyltransferase, } \\
\text { DNA polymerase } \\
\text { processivity factor } \\
\text { (UL42) }\end{array}$ & NO & NO \\
\hline 3260284 & NO & NO & $\begin{array}{l}\text { Anti-sigma-28 factor, } \\
\text { FlgM }\end{array}$ & NO & NO \\
\hline$\underline{3260290}$ & $\begin{array}{l}\text { MazG nucleotide } \\
\text { pyrophosphohydrolas } \\
\text { e domain }\end{array}$ & $\begin{array}{l}\text { NTP } \\
\text { pyrophosphohydrolas } \\
\text { e MazG, putative } \\
\text { catalytic core; NTP } \\
\text { Pyrophosphohydrolas } \\
\text { e MazG-related, } \\
\text { GP37 }\end{array}$ & $\begin{array}{l}\text { MazG nucleotide } \\
\text { pyrophosphohydrolas } \\
\text { e domain }\end{array}$ & $\begin{array}{l}\text { Predicted } \\
\text { pyrophosphatase }\end{array}$ & 2gtaA -11- 58- $8 \mathrm{e}-10$ \\
\hline$\underline{3260294}$ & $\begin{array}{l}\text { clamp loader small } \\
\text { subunit }\end{array}$ & $\mathrm{NO}$ & NO & NO & NO \\
\hline 3260299 & NO & $\mathrm{NO}$ & Clavanin & NO & NO \\
\hline 3260300 & MoxR-like ATPases & ATPase, AAA-5 & $\begin{array}{l}\text { AAA domain } \\
\text { (dynein-related } \\
\text { subfamily), } \\
\text { CbbQ/NirQ/NorQ C- } \\
\text { terminal }\end{array}$ & MoxR-like ATPases & $2 \mathrm{r} 44 \mathrm{~A}-16-205-7 \mathrm{e}-54$ \\
\hline 3260301 & $\mathrm{NO}$ & $\mathrm{NO}$ & $\begin{array}{l}\text { Neurotransmitter- } \\
\text { gated ion-channel } \\
\text { transmembrane } \\
\text { region }\end{array}$ & $\mathrm{NO}$ & $\mathrm{NO}$ \\
\hline 3260309 & $\mathrm{NO}$ & NO & $\begin{array}{l}\text { Virion protein } \mathrm{N} \\
\text { terminal domain } \\
\text { Fibrillar collagen } \mathrm{C} \text { - } \\
\text { terminal domain }\end{array}$ & $\mathrm{NO}$ & $\mathrm{NO}$ \\
\hline$\underline{3260312}$ & $\mathrm{NO}$ & NO & $\begin{array}{l}\text { GnsA/GnsB family, } \\
\text { IncA protein } \\
\text {,Prefoldin subunit } \\
\text {,Calcium binding and } \\
\text { coiled-coil domain } \\
\text { (CALCOCO1) like, } \\
\text { Rho Binding } \\
\text {,Microtubule-binding } \\
\text { stalk of dynein motor }\end{array}$ & $\mathrm{NO}$ & NO \\
\hline$\underline{3260316}$ & NO & $\begin{array}{l}\text { Pectin lyase } \\
\text { fold/virulence factor }\end{array}$ & $\mathrm{NO}$ & NO & NO \\
\hline 3260319 & NO & $\mathrm{NO}$ & $\begin{array}{l}\text { EAP30/Vps36 family } \\
\text {,Vps51/Vps67, } \\
\text { Prefoldin subunit }\end{array}$ & NO & $\mathrm{NO}$ \\
\hline 3260320 & $\mathrm{NO}$ & $\mathrm{NO}$ & $\begin{array}{l}\text { BRE1 E3 ubiquitin } \\
\text { ligase }\end{array}$ & $\mathrm{NO}$ & $\mathrm{NO}$ \\
\hline 3260327 & $\mathrm{NO}$ & $\mathrm{NO}$ & $\begin{array}{l}\text { Transcriptional } \\
\text { activator HlyU }\end{array}$ & $\mathrm{NO}$ & $\mathrm{NO}$ \\
\hline 3260330 & $\mathrm{NO}$ & $\mathrm{NO}$ & $\begin{array}{l}\text { Firmicute eSAT-6 } \\
\text { protein secretion } \\
\text { system EssA }\end{array}$ & $\mathrm{NO}$ & $\mathrm{NO}$ \\
\hline 3260331 & Peptidase family M23 & $\begin{array}{l}\text { Duplicated hybrid } \\
\text { motif,Peptidase M23 }\end{array}$ & Peptidase family M23 & $\begin{array}{l}\text { Membrane proteins } \\
\text { related to } \\
\text { metalloendopeptidase } \\
\text { S }\end{array}$ & NO \\
\hline 3260332 & $\begin{array}{l}\text { Protein Disulfide } \\
\text { Oxidoreductases and } \\
\text { Other Proteins with a } \\
\text { Thioredoxin fold }\end{array}$ & $\begin{array}{l}\text { NAD:arginine ADP- } \\
\text { ribosyltransferase, } \\
\text { ART,Arsenate } \\
\text { reductase-like }\end{array}$ & $\begin{array}{l}\text { NAD:arginine ADP- } \\
\text { ribosyltransferase, } \\
\text { ArsC family }\end{array}$ & $\begin{array}{l}\text { Methyl-accepting } \\
\text { chemotaxis protein }\end{array}$ & $\mathrm{NO}$ \\
\hline
\end{tabular}




\begin{tabular}{|c|c|c|c|c|c|}
\hline$\underline{3260338}$ & $\mathrm{NO}$ & $\mathrm{NO}$ & $\begin{array}{l}\text { TM1410 } \\
\text { hypothetical-related } \\
\text { protein }\end{array}$ & NO & NO \\
\hline$\underline{3260341}$ & $\mathrm{NO}$ & $\mathrm{NO}$ & $\begin{array}{l}\text { Second } \\
\text { Mitochondria-derived } \\
\text { Activator of Caspases }\end{array}$ & $\mathrm{NO}$ & $\mathrm{NO}$ \\
\hline 3260347 & NO & NO & $\begin{array}{l}\text { FtsX-like permease } \\
\text { family }\end{array}$ & NO & NO \\
\hline$\underline{3260350}$ & NO & $\mathrm{NO}$ & $\begin{array}{l}\text { FIP domain,Paired } \\
\text { amphipathic helix } \\
\text { repeat }\end{array}$ & NO & NO \\
\hline$\underline{3260355}$ & $\mathrm{NO}$ & $\mathrm{NO}$ & $\begin{array}{l}\text { Hypothetical protein } \\
\text { (DUF2410) } \\
\text {,Transcription- } \\
\text { initiator DNA- } \\
\text { binding domain IBD }\end{array}$ & $\mathrm{NO}$ & NO \\
\hline 3260357 & NO & $\mathrm{NO}$ & $\begin{array}{l}\text { Glucitol operon } \\
\text { activator protein } \\
\text { (GutM) }\end{array}$ & NO & $\mathrm{NO}$ \\
\hline$\underline{3260359}$ & $\begin{array}{l}\text { 2OG-Fe(II) } \\
\text { oxygenase } \\
\text { superfamily }\end{array}$ & $\begin{array}{l}\text { Oxoglutarate/iron- } \\
\text { dependent } \\
\text { oxygenase,Prolyl 4- } \\
\text { hydroxylase, alpha } \\
\text { subunit }\end{array}$ & $\begin{array}{l}\text { 2OG-Fe(II) } \\
\text { oxygenase } \\
\text { superfamily,Poxvirus } \\
\text { C4/C10 protein }\end{array}$ & $\mathrm{NO}$ & $2 \mathrm{hbtA}-17-73-5 \mathrm{e}-14$ \\
\hline 3260360 & $\mathrm{NO}$ & $\mathrm{NO}$ & $\begin{array}{l}\text { Vanadium/alternative } \\
\text { nitrogenase delta } \\
\text { subunit }\end{array}$ & $\mathrm{NO}$ & $\mathrm{NO}$ \\
\hline$\underline{3260362}$ & $\mathrm{NO}$ & $\mathrm{NO}$ & $\begin{array}{l}\text { Survival motor } \\
\text { neuron protein } \\
(\mathrm{SMN})\end{array}$ & $\mathrm{NO}$ & $\mathrm{NO}$ \\
\hline$\underline{3260370}$ & $\mathrm{NO}$ & $\mathrm{NO}$ & $\begin{array}{l}\text { Mitochondrial inner } \\
\text { membrane protein } \\
\text { Chlamydia-phage } \\
\text { Chp2 scaffold } \\
\text { (Chlamy_scaf), } \\
\text { Ribosomal L29 } \\
\text { protein }\end{array}$ & $\mathrm{NO}$ & NO \\
\hline 3260373 & $\mathrm{NO}$ & $\mathrm{NO}$ & $\begin{array}{l}\text { Pedibin/Hym-346 } \\
\text { family }\end{array}$ & $\mathrm{NO}$ & $\mathrm{NO}$ \\
\hline 3260380 & $\mathrm{NO}$ & $\mathrm{NO}$ & $\begin{array}{l}\text { Signal transducing } \\
\text { histidine kinase, } \\
\text { homodimeric domain; } \\
\text { Bacillus haemolytic } \\
\text { enterotoxin } \\
\text { (HBL);Coat F } \\
\text { domain;HOOK } \\
\text { protein;Autophagy } \\
\text { protein 16 } \\
\text { (ATG16);Outer } \\
\text { membrane protein } \\
\text { (OmpH-like); } \\
\text { Plasmid replication } \\
\text { region DNA-binding } \\
\text { N-term;GDP/GTP } \\
\text { exchange factor } \\
\text { Sec2p; Reovirus } \\
\text { sigma C capsid } \\
\text { protein; PspA/IM30 } \\
\text { family; Laminin } \\
\text { Domain II; } \\
\text { Microtubule } \\
\text { associated; Rab5 } \\
\text { binding; Intermediate } \\
\text { filament protein; } \\
\text { Apolipophorin-III } \\
\text { precursor (apoLp-III) } \\
\text {; ATP synthase } \\
\text { subunit D ; Uso1 / } \\
\text { p115 like vesicle } \\
\text { tethering protein, C } \\
\text { terminal region }\end{array}$ & $\mathrm{NO}$ & NO \\
\hline
\end{tabular}




\begin{tabular}{|c|c|c|c|c|c|}
\hline & & & $\begin{array}{l}\text {;Seryl-tRNA } \\
\text { synthetase N-terminal } \\
\text { domain ; Phage } \\
\text { capsid scaffolding } \\
\text { protein }(\mathrm{GPO}) \text { serine } \\
\text { peptidase ; SlyX ; } \\
\text { Baculovirus } \\
\text { polyhedron envelope } \\
\text { protein, PEP, C } \\
\text { terminus ; FlgN } \\
\text { protein ; Prominin ; } \\
\text { Tat binding protein } \\
\text { 1(TBP-1)-interacting } \\
\text { protein (TBPIP) } \\
\text {;Axonemal dynein } \\
\text { light chain ; Subunit } \\
21 \text { of Mediator } \\
\text { complex ;bZIP } \\
\text { transcription factor } \\
\text {;Tektin family } \\
\text {;Homeobox } \\
\text { associated leucine } \\
\text { zipper ;JNK_SAPK- } \\
\text { associated protein-1; } \\
\text { Intra-flagellar } \\
\text { transport protein 57 } \\
\text {;Transposase protein } \\
\text {;Spc7 kinetochore } \\
\text { protein ;Cortexillin I, } \\
\text { coiled coil ;UV } \\
\text { radiation resistance } \\
\text { protein and } \\
\text { autophagy-related } \\
\text { subunit } 14 \\
\text {;MbeD/MobD like } \\
\text {;DASH complex } \\
\text { subunit Spc34 } \\
\text { F;Septum formation } \\
\text { initiator; USP8 } \\
\text { interacting; } \\
\text { Nucleopolyhedroviru } \\
\text { s P10 protein ; IncA } \\
\text { protein ;TATA } \\
\text { element modulatory } \\
\text { factor } 1 \text { DNA binding } \\
\text {; Transcription factor } \\
\text { Opi1 ; Cartilage } \\
\text { oligomeric matrix } \\
\text { protein ;Ribosomal } \\
\text { L29 protein } \\
\end{array}$ & & \\
\hline$\underline{3260383}$ & $\mathrm{NO}$ & $\mathrm{NO}$ & $\mathrm{NO}$ & $\mathrm{NO}$ & $\mathrm{NO}$ \\
\hline$\underline{3260385}$ & NO & NO & $\mathrm{NO}$ & $\mathrm{NO}$ & NO \\
\hline$\underline{3260386}$ & $\mathrm{NO}$ & $\mathrm{NO}$ & $\begin{array}{l}\text { Alpha mannosidase, } \\
\text { middle domain }\end{array}$ & $\mathrm{NO}$ & $\mathrm{NO}$ \\
\hline$\underline{3260388}$ & $\begin{array}{l}\text { 2OG-Fe(II) } \\
\text { oxygenase } \\
\text { superfamily }\end{array}$ & NO & $\mathrm{NO}$ & $\mathrm{NO}$ & 2hbtA -14 -62 -6e-11 \\
\hline 3260389 & $\begin{array}{l}\text { 2OG-Fe(II) } \\
\text { oxygenase } \\
\text { superfamily }\end{array}$ & $\begin{array}{l}\text { Oxoglutarate/iron- } \\
\text { dependent } \\
\text { oxygenase,Prolyl 4- } \\
\text { hydroxylase, alpha } \\
\text { subunit }\end{array}$ & $\begin{array}{l}\text { 2OG-Fe(II) } \\
\text { oxygenase } \\
\text { superfamily }\end{array}$ & $\mathrm{NO}$ & 2jigA -16 -76- 4e-15 \\
\hline$\underline{3260392}$ & $\mathrm{NO}$ & $\mathrm{NO}$ & UvrB/uvrC motif & $\mathrm{NO}$ & $\mathrm{NO}$ \\
\hline$\underline{3260393}$ & $\mathrm{NO}$ & $\mathrm{NO}$ & $\begin{array}{l}\text { SpoVT / AbrB like } \\
\text { domain }\end{array}$ & NO & $\mathrm{NO}$ \\
\hline$\underline{3260394}$ & NO & $\mathrm{NO}$ & $\begin{array}{l}\text { Fork head domain , } \\
\text { Transcription factor } \\
\text { Vhr1 }\end{array}$ & $\mathrm{NO}$ & $\mathrm{NO}$ \\
\hline$\underline{3260396}$ & $\mathrm{NO}$ & NO & $\begin{array}{l}\text { Mis12-Mtw1 protein } \\
\text { family }\end{array}$ & $\mathrm{NO}$ & NO \\
\hline
\end{tabular}




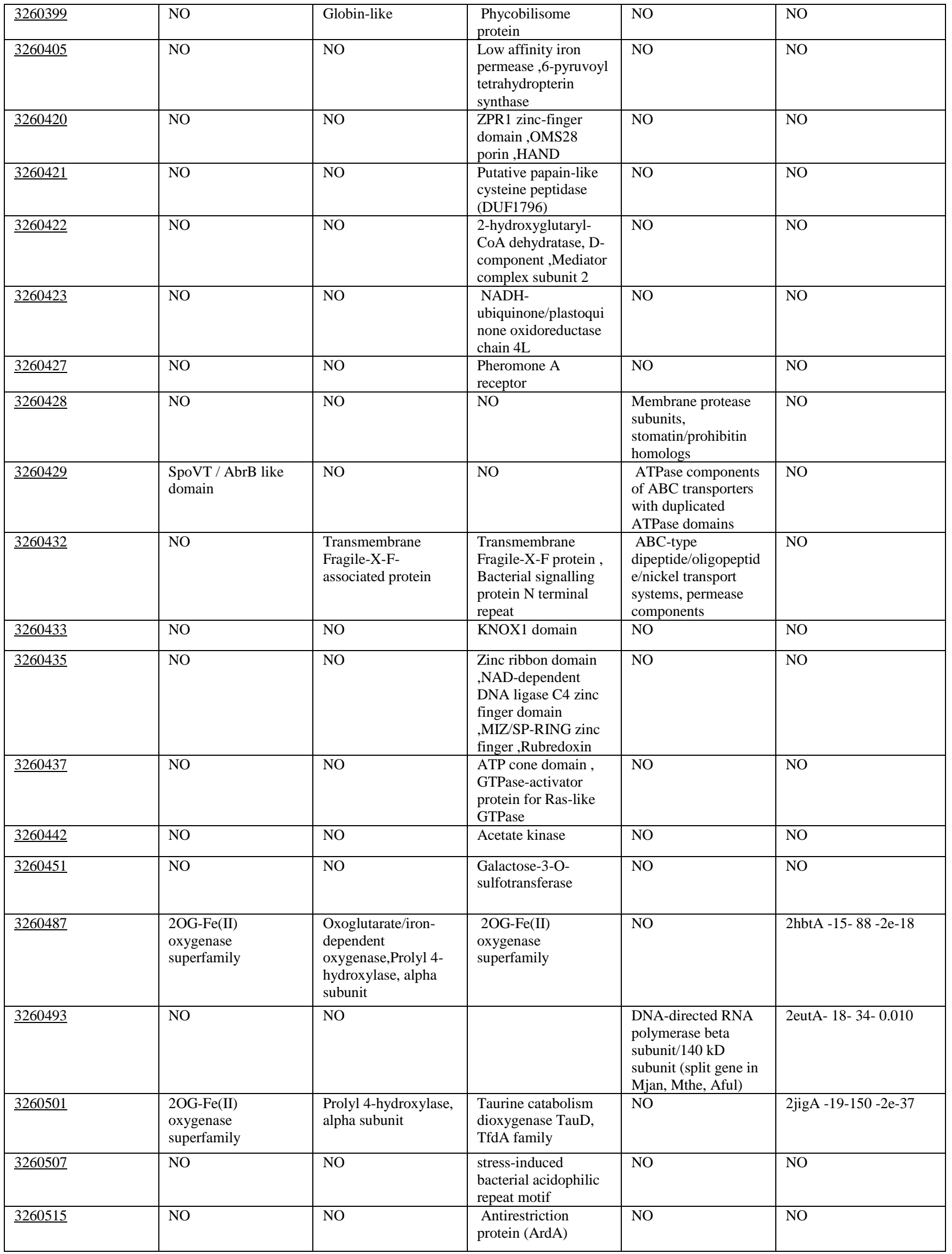


Table 9 Structure and Functional Data for SYNECHOCOCCUS PHAGE SYN9

\begin{tabular}{|c|c|c|c|c|c|}
\hline NCBI Gene & CDD-Blast & Interproscan & pfam & COGs & Structures \\
\hline 4239015 & No & No & $\begin{array}{l}\text { VP_N-CPKC Virion } \\
\text { protein } \mathrm{N} \text { terminal } \\
\text { domain }\end{array}$ & No & No \\
\hline 4239049 & No & No & $\begin{array}{l}\text { Poxvirus C7/F8A } \\
\text { protein }\end{array}$ & No & No \\
\hline
\end{tabular}

Table 10 Structure and Functional Data for SYNECHOCOCCUS PHAGE SYN5

\begin{tabular}{|l|l|l|l|l|l|}
\hline NCBI Gene & CDD-Blast & Interproscan & pfam & COGs \\
\hline 5220168 & No & $\begin{array}{l}\text { Acyl-CoA N- } \\
\text { acyltransferase }\end{array}$ & No & No & No \\
\hline 5220169 & No & No & $\begin{array}{l}\text { GHMP kinases C } \\
\text { terminal }\end{array}$ & No \\
\hline
\end{tabular}

\section{CONCLUSIONS}

This in-silico study have sorted some functionally important hypothetical proteins of cyanophages applying the parameters of pair-wise and multiple sequence alignment tools along with structure prediction tools, which suggests that many probable functional uncharacterized proteins are available in the cyanophages. Bioinformatics Web Tools have shown the ability to predict structure and functions in 258 hypothetical proteins of cyanophages. In all 28 3-D structures for

\section{ACKNOWLEDGMENTS}

We thanks to all the researchers who have contributed for preparation and reviewing of this manuscript.

\section{REFERENCES}

[1] Alex, B., Lachlan, C., Richard, D., Robert, D. F., Volker, H., Sam, G.J., Ajay, K., Mhairi, M., Simon, M., Erik, L. L. S., David, J. S., Corin Y., Sean, R. E. The Pfam families' database. Nucleic Acids Research, Vol. 32, D138-D141, 2004.

[2] Altschul, S., F., Madden, T., L., Schaffer, A., A., Zhang, J., Zhang, Z., Miller, W., Lipman, D., J. Gapped BLAST and PSI-BLAST: a new generation of protein database search programs. Nucleic Acids Res. 25 (17), 3389-402, 1997.

[3] Aron, M. Bauer., John, B. A., Myra, K. D., Carol, D. S., Noreen, R. G., Marc, G., Luning, H., Siqian, H., David, I. H., John, D. J., Zhaoxi, K., Dmitri, K., Christopher, J. L.,Cynthia A. L., Chunlei, L., Fu, L., Shennan, L., Gabriele, H. M., Mikhail, M., James, S. S., Narmada, T., Roxanne, A. Y., Jodie, J. Y., Dachuan, Z., Stephen, H. B. CDD: a conserved domain database for interactive domain family analysis. Nucleic Acids Research, Vol. 35, D237-D240, 2006.

[4] Baba, T., Takeuchi, F., Kuroda, M., Yuzawa, H., Aoki, K., Oguchi, A., et al. Genome and virulence determinants of high virulence community-acquired MRSA. Lancet 359: 1819-1827, 2002.

[5] Barre, F.X., and Sherratt, D.J. Xer site-specific recombination: promoting chromosome segregation. In Mobile DNA II, 2002.

[6] Breitbart, M., Thompson, L.R., Suttle, C.A., Sullivan, M. B. Exploring the Vast Diversity of Marine Viruses. Oceanogr 20: 135-139, 2007. hypothetical proteins was constructed using (PS) ${ }^{2}$ server, which serves as a fast automated 3D- structure generating web server. This predicted three dimensional structures may assist in establishing their importance in life cycle of cyanophages whose exact role in phage-host lifecycle is still unclear and can be used in future for the understanding of functional, structural and evolutionary development of cyanophages and its life cycle along with their role in host evolution.

[7] Canchaya, C., Proux, C., Fournous, G., Bruttin, A., and Brussow, H. Prophage genomics. Microbiol Mol Biol Rev 67: 238-276, 2003.

[8] Casjens, S. Prophages and bacterial genomics: what have we learned so far? Mol Microbiol 49: 277-300, 2003.

[9] Cédric, N., Desmond, G. H., Jaap, H. T-coffee: a novel method for fast and accurate multiple sequence alignment. J. Mol. Biol. 302, 205-217, 2000.

[10] Chen, F. and Lu, J. Genomic sequence and evolution of marine cyanophage P60: a new insight on lytic and lysogenic phages. Appl. Environ. Microbiol. 68 (5), 2589-2594,2002.

[11] Chih-Chieh, C., Jenn-Kang, H., Jinn-Moon, Y. (PS)2: protein structure prediction server Nucl. Acids Res. 34, W152-W157, 2006.

[12] Edward, E., Gary, L. G., Osnat, H., John, M., John, O., Roberto, J. P., Linda, B., Delwood, R., Andrew, J. H. Biological function made crystal clear- annotation of hypothetical proteins via structural genomics. Current Opinion in Biotechnology 11, 25-30, 2000.

[13] Fuhrman, J. A. Marine viruses and their biogeochemical and ecological effects. Nature 399: 541-8,1999.

[14] Mann, N.H., Clokie, M.R., Millard, A., Cook, A., Wilson, W.H., Wheatley, P.J., Letarov, A. and Krisch, H. M. The genome of S-PM2, a 'photosynthetic' T4-type bacteriophage that infects marine Synechococcus strains. J. Bacteriol. 187 (9), 3188-3200, 2005.

[15] Millard, A. D., Zwirglmaier, K., Downey, M.J., Mann, N.H. H. and Scanlan, D. J. Comparative genomics of marine cyanomyoviruses reveals the widespread occurrence of Synechococcus host genes localized to a hyperplastic region: implications for mechanisms of cyanophage evolution. Environ. Microbiol. 11 (9), 2370$2387,2009$. 
[16] Paul, J. H. and Sullivan, M. B. Marine phage genomics: what have we learned? Curr Opin Biotechnol 16: 299$307,2005$.

[17] Pope,W.H., Weigele,P.R., Chang,J., Pedulla,M.L., Ford,M.E., Houtz,J.M., Jiang,W., Chiu,W., Hatfull,G.F., Hendrix,R.W. and King, J. Genome sequence, structural proteins, and capsid organization of the cyanophage Syn5: a 'horned' bacteriophage of marine Synechococcus. J. Mol. Biol. 368 (4), 966-981, 2007.

[18] Roman, L. T., Michael, Y., Galperin, Darren A. Natale, Eugene V. Koonin. The COG database: a tool for genome -scale analysis of protein functions and evolution. Nucleic Acid Research. 28, 33-36, 2000.

[19] Schaffer, A. A., Aravind, L., Madden, T. L., Shavirin, S. Spouge, J. L., Wolf, Y. I., Koonin, E. V., Altschul, S. F. Improving the accuracy of PSI-BLAST protein database searches with composition-based statistics and other refinements. Nucleic Acids Res. 29(14), 2994-3005, 2001.

[20] Simpson, A.J., Reinach, F.C., Arruda, P., Abreu, F.A., Acencio, M., Alvarenga, R., et al. The genome sequence of the plant pathogen Xylella fastidiosa. The Xylella fastidiosa Consortium of the Organization for Nucleotide Sequencing and Analysis. Nature 406: 151-157, 2002.

[21] Smoot, J.C., Barbian, K.D., Van Gompel, J.J., Smoot, L.M., Chaussee, M.S., Sylva, G.L., et al. Genome sequence and comparative microarray analysis of serotype M18 group A Streptococcus strains associated with acute rheumatic fever outbreaks. Proc Natl Acad Sci USA 99: 4668-4673, (2002).

[22] Smoot, L.M., Smoot, J.C., Graham, M.R., Somerville, G.A., Sturdevant, D.E., Migliaccio, C.A., et al. Global differential gene expression in response to growth temperature alteration in group A Streptococcus. Proc Natl Acad Sci USA 98: 10416-10421, 2001.

[23] Sullivan, M. B., Huang, K. H., Ignacio-Espinoza, J. C., Berlin, A. M., Kelly, L., Weigele, P. R., Defrancesco, A. S., Kern, S. E., Thompson, L. R., Young, S., Yandava, C., Fu, R., Krastins, B., Chase, M., Sarracino, D., Osburne, M. S., Henn, M. R. and Chisholm, S. W. Genomic analysis of oceanic cyanobacterial myoviruses compared with T4-like myoviruses from diverse hosts and environments. Environ. Microbiol. 12 (11), 30353056, 2010.

[24] Sullivan, M. B., Krastins, B., Hughes, J. L., Kelly, L., Chase, M., Sarracino, D. and Chisholm, S.W. The genome and structural proteome of an ocean siphovirus: a new window into the cyanobacterial 'mobilome'. Environ. Microbiol. 11 (11), 2935-2951, 2009.

[25] Suttle, C. A. Viruses in the sea. Nature 437: 356-61, 2005.

[26] Swapnil, G. S., Dilip, B. M., Waman, N. P., Tarun, K. G. Computational characterizations for structure and function of unclassified proteins in Ictalurus punctatus. CiiT International Journal of Artificial Intelligent
Systems and Machine Learning DOI: AIML052011001, 2011.

[27] Swapnil, G. S., Waman, N. P. Study of hypothetical proteins in Shigella phages. CiiT International Journal of fuzzy Systems 2011.

[28] Swapnil, G. S., Waman, N. P., Dilip, B. M., Tarun, K. G. Functionality search in hypothetical proteins of Halobacterium salinarum CiiT International Journal of fuzzy Systems 2011.

[29] Swapnil, G. S., Waman, N. P., Dilip, B. M., Tarun, K. G. Insilico function prediction for hypothetical proteins in Vibrio parahaemolyticus Chromosome II. CiiT International Journal of Data Mining and Knowledge Engineering. DOI: DMKE052011003, 2011.

[30] Swapnil, G. S., Waman, N. P., Tarun, K. G. Computational approach for structure and functionality search for hypothetical proteins in Mycobacterium leprae CiiT International Journal of Data Mining and Knowledge Engineering DOI: DMKE032011014, 2011.

[31] Swapnil, G S., Waman, N. P., Tarun, K G. Study of Hypothetical Proteins in Salmonella Phages and Predicting their Structural and Functional Relationship CiiT International Journal of Biometrics and Bioinformatics. DOI: BB022011001, 2011.

[32] Swapnil, G. S., Waman, N. P., Tarun, K. G. \& Tapan, C. Structure and Function Predictions of Hypothetical Proteins in Vibrio Phages. International Journal of Biometrics and Bioinformatics. 4, 161-175, 2010.

[33] Waman, N. P., Swapnil, G. S. and Tarun, K. G. Exploring the hypothetical proteins in Rizhophages and their role in influencing Rhizobium species in soil. CiiT International Journal of Artificial Intelligent systems and Machine Learning DOI: AIML042011002, 2011.

[34] Weigele,P.R., Pope,W.H., Pedulla,M.L., Houtz,J.M., Smith, A. L., Conway, J. F., King,J., Hatfull,G.F., Lawrence, J. G. and Hendrix,R.W. Genomic and structural analysis of Syn9, a cyanophage infecting marine Prochlorococcus and Synechococcus. Environ. Microbiol. 9 (7), 1675-1695, 2007.

[35] Whiteley, M., Bangera, M.G., Bumgarner, R.E., Parsek, M.R., Teitzel, G.M., Lory, S., and Greenberg, E.P. Gene expression in Pseudomonas aeruginosa biofilms. Nature 413: 860-864, 2001.

[36] Yoshida,T., Nagasaki,K., Takashima,Y., Shirai,Y., Tomaru,Y., Takao,Y., Sakamoto,S., Hiroishi,S. and Ogata,H. Ma-LMM01 infecting toxic Microcystis aeruginosa illuminates diverse cyanophage genome strategies. J. Bacteriol. 190 (5), 1762-1772, 2008.

[37] Zafer, A., Yucel, A., Mark, B. Protein secondary structure prediction for a single-sequence using hidden semi-Markov models, BMC Bioinformatics ,7, 178, 2006.

[38] Zdobnov, E. M., Rolf, A. Interproscan- an integration platform for the signatures recognition methods in InterPro. Bioinformatics 17,847-848, 2001. 